\title{
Value Engineering in Building Information Modelling for Cost Optimization of Renovation Works: a Case Study
}

\author{
Fathoni Usman ${ }^{1 *}$, Nur Adibah Jalaluddin ${ }^{2}$, Sumi Amariena Hamim ${ }^{3}$ \\ ${ }^{1}$ Institute of Energy Infrastructure, Universiti Tenaga Nasional, Kajang, Malaysia \\ ${ }^{2}$ College of Engineering, Universiti Tenaga Nasional, Kajang, Malaysia \\ ${ }^{3}$ Universitas Indo Global Mandiri, Palembang, Indonesia \\ *Corresponding author E-mail: fathoni@uniten.edu.my
}

\begin{abstract}
Implementation of Value Engineering (VE) in the construction industry has become a proven technique for cost optimization. This paper presents a review of the implementation of BIM in construction industry. The factors that triggered and hinder the implementation of VE and BIM in the current industry and a case study of the application of VE using BIM for cost optimization of renovation works are also discussed. The project which was used for the case study is the renovation of shop lot units to be used as a student centre where student activities will be placed. 3D models of the project were developed as BIM model that provide strong visualization when creating alternatives for VE processes. The function analysis, risk analysis and life-cycle cost analysis were applied to determine the value index for each developed alternative. It shows that the implementation had successfully reduced the cost by approximately $27 \%$ and the value of the project increased after the process.
\end{abstract}

Keywords: Value Engineering; Building Information Modelling; renovation; cost optimization.

\section{Introduction}

Value Engineering (VE) is a systematic process to advance the values of goods, products or services. It is defined as the performance to cost ratio; to increase the performance or to reduce the cost. In the recent construction Industry, value engineering was to be practised ensuring an objective-oriented project or costoptimized projects were achieved. The VE has been used in numerous countries around the world for half a century in construction industry with diverse challenges to achieve high value projects on time and within budget [1][2].

The Value Engineering was also described as an integrated management of problem-solving implementation functions, design alternatives, cost-driven decision and performance driven project objectives in structured and conscious selection criteria [3]. The idea of VE has been considered for many years by governments and private firms especially in the construction industry as to increase efficiency and reducing the cost of projects. As claimed [2], VE has become a common practice for many governments and private engineering agencies and contractors since its first adoption in the 1950s. Dell'isola stated that the VE technique can be used to achieve many objectives such as saving money, reducing time, improving performances etc. [4].

Modern developments in ICT technology related to the construction industry are now commonplace for facilitating various activities such as cost estimation, visualization and rendering, failure analysis, documentation components, fault and clash location, repair and reconstruction. The Building Information Modelling (BIM) is a process where the physical features and information of every element of the project is digitalized regard to its required level of detail [5]. In other words, $\mathrm{BIM}$ is to digitalize the information in 3D graphic making it easier to be analysed. The BIM has existed since a few decades ago, but due to the deficiency of information technology system, BIM could not be practised until a few years ago. Bhatija et.al. stated that BIM has been in existence for as over as 30 years, however, it only has known in 2002 when Autodesk released it to its users [6]. Regarding the BIM implementation level, many countries have started to enforce BIM implementation in most of their projects. For example, The US government is moving to require BIM on all their building projects since 2003. The UK government Construction Strategy was prompted in 2011 to require BIM implementation on every government project by 2016 through a 5year staged implementation plan. The Germany government with industry player established Digital Building Platform in 2015 as their national BIM strategy. The Singapore government established a Construction Productivity and Capability Fund (CPCF) of S\$ 250 million with BIM as the key target and the implementation of BIM have been mandated for projects greater than 5,000 $\mathrm{m}^{2}$ since 2015[7].

The construction industry in Malaysia, according to the Construction Industrial Development Board, CIDB have been put as one of the important parts in Malaysian economy although it only contributes to approximately $3 \%-5 \%$ of the gross domestic products annually [8]. The BIM implementation in Malaysia construction industry slightly left behind compared UK, Germany or event Singapore [9]. Memon et.al. in [5] found that BIM implementation in Malaysia is still infant which needs observation and serious effort in achieving the thriving construction projects. The BuildingSMART Malaysia stated that the participation of government of Malaysia in BIM implementation began through the first project using BIM officially in 2012, which is the National Cancer Institute in Sepang. To date, CIDB has a record of over 20 projects utilizing the BIM concept [10]. 
To improve construction building quality, studies have been conducted to correlate VE and BIM to ensure cost optimization in the projects. Forgues et.al. as in [11] claimed that potential faster and more cost-effective project delivery process, higher quality buildings can be delivered by performing VE from the beginning of design process and it would increase control and predictability for its owner. They examined the changes in work practices and workflows within a construction company as they move towards adopting BIM estimating process. Furthermore, a study by Ranjbaran and Moselhi as in [3] integrated the project's BIM model with RSMeans cost data and AHP (Analytic Hierarchy Process) which was based on the VE and a prototype model.

This paper will determine to what extent the BIM implementation in VE for cost optimization in Malaysia Construction Industry. The objectives are to determine the factors triggering and hurdling the BIM implementation in VE for cost optimization and compare the traditional method which is based on literature review. This paper also presents a case study on remodelling completed project of student centre of Universiti Tenaga Nasional (UNITEN) using BIM with VE for cost estimation and optimization implementing LCCA.

\section{BIM and VE Implementation}

Figure 1 shows the hurdling factor of implementing BIM in construction industry. It stated that $40 \%$ of the hurdling factors is the industry player awareness and uptake towards this development. The lack of BIM outside the design environment is the result of the slow uptake in the new adoption technologies throughout the AEC industry sector [12]. Many parties involved in the industry claimed that the information on BIM is not sufficient, and this system is a very new system that it would take time to be implemented. The worst case is, some also doesn't even know the BIM system, let alone the VE in this industry.

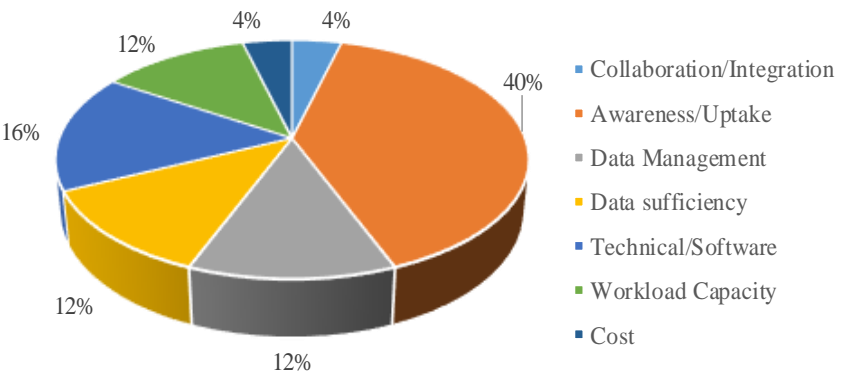

Fig. 1: Hurdling Factors

In their study, Yan et.al. as in [13] emphasized on how the BIM implementation has lacking awareness. Due to this fact, the personnel involved would not want to learn or know about the system. Lacking awareness means a lot of needed elements such as training and enforcement were not carried out by the involved party. The awareness factor also touched on the BIM maturity level, where some company was not aware of this level. The level of BIM where a few countries already started to push the construction industry to the higher level of maturity. Consequently, many small companies are being unaware or ignorance of this implementation and are having trouble to catch up with the current technology implementation [14]. This scenario will cause a different level of BIM implementation and it will then be hard for the company to collaborate with other company. It was also found that the reluctance of some management in provisioning to implement the new technologies caused the low implementation [14].

There is not yet any case claiming that BIM is not appropriate to be implemented. Researchers believe that implementing BIM will reduce the gap between predicted and actual building performance which can be implied using the BIM ready software such as
Autodesk REVIT, ArchiCAD etc. [12]. BIM also have observed to help reducing error during early phase until the maintenance phase including the cost in design and construction. Smith et.al. in [7] and Tulenheimo in [14] supported the statement saying BIM help speeding up the design process and maximize the efficiency of the project.

In another article, BIM was said to reduce the gap of difference between predicted and actual building performance, optimize operational efficiency and reduce the error of construction from the designing stage [12]. The BIM was also proved by Tulenheimo to speed up the design process [14]. In addition, Azhar stated that BIM was efficiently used to decrease project cost and reducing the delivery time of a project [15]. The study emphasized that BIM brings better design and better customer service by enabling visualization through the $3 \mathrm{D}$ generated model as well [15].

The BIM is proved to be a very excellence tool to facilitate Value Engineering in the current stage of the industry. In a study, Wormald stated a few projects which has been utilizing BIM to optimize VE exercise and the result obtain were $32 \%$ cost saving, no material wastage as all pre-cut or ordered for prefabrication in a controlled environment, included approximately saving at average $4 \%$ wastage [15].

\section{Methodology}

\subsection{Implementation of VE for Cost Optimization}

The objective of the VE exercise in construction projects is to achieve the necessary functions with the possible lowest project life cycle cost [2]. This may be applied to a lot of initiatives such as new material, creative design, simplified process, innovative construction method, reduced construction cost and time, improved quality and safety. To achieve the VE objective, the implementation of BIM, as well as the Life Cycle Cost Analysis (LCCA), were expected to facilitate the process in this case study. The complete phases of a VE exercise will be as follow:

a) Information phase. In this phase, data concerning the product (or service under study) need to be gathered from the concern and best sources and should be supported by tangible evidence.

b) Function identification and analysis phase. The function identification and analysis phase are the essential phase of the VE study. The objective of this phase is to convert the information collected in terms of objectives and requirements to functions [16], [17]. The functions are defined using twowords an active verb and a measurable noun. The functions present in a schematic diagram that shows how a project element could be achieved and why these elements are needed in achieving the project value objectives. Function analysis is used in identifying wastage, duplication, unnecessary cost and opportunities for improvement.

c) Creative phase. In this phase, the creative techniques used to identify other ways to perform the project's functions by selecting the elements that do the functions. Techniques that may be used at this stage include brainstorming, reasoned debate, prioritized function model, multi-attribute rating technique etc [17], [18].

d) Evaluation phase. A structured evaluation process is followed to select the ideas that offer the potential for value improvement while delivering the project's functions and considering performance requirements and resource limits [17].

e) Development and presentation phases. In these two phases, the selected ideas are developed to alternatives or proposals and presented to the decision makers with justifications [17].

For this case study, the VE exercise is conducted up to the evaluation phase and implementing the LCCA. 


\subsection{Application of BIM}

The data needed for modelling and cost estimates were obtained from Facilities Development \& Management (FDM) UNITEN. The data was converted into BIM model using Autodesk REVIT where the quantity and cost of materials can be determined. The software can be used in planning, developing and monitoring through various stages of the lifecycle of a project starting from a concept to completing execution, maintenance, and demolition. The software provides different visualization experiences to the practitioner to capture and analyse concepts through design, documentation, and construction [5]. The alternatives for VE exercises were developed based on the objective of the project and evaluating rendered model images. The changing of value index was then evaluated using the LCCA.

\section{Discussion}

\subsection{Value Engineering - Information Phase}

The objectives of providing new student centre are to provide meeting rooms and to provide an activity hall for students. An interview session was conducted to gather the information on the functionality of the student centre. The layout plan obtained was then generated into a 3D model. The 3D model is much easier and convenient to be used in helping to improve the project in terms of nearly every aspect i.e. architecture, engineering, construction, etc. Fig. 3 shows the 3D model developed based on the obtained building drawings.

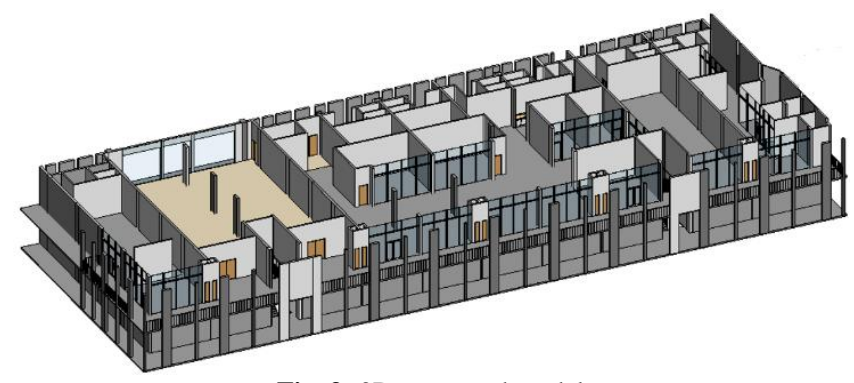

Fig. 3: 3D generated model

Generating a 3D model would certainly help to synchronize the imaginary view of the personnel involved in the VE exercise so that a good measure could be implied. After the 3D model generated, the cost of the project is estimated. In this study, the overall cost will be only based on the floor finishes. The initial cost of the floor finishes calculated is RM 285,315.90.

Implementing VE in BIM means that, the objectives of the project will certainly be evaluated throughout every stage of the project, from the planning stage until the maintenance stage visually. This is to ensure that the project or the facility serve their optimum purpose. Since the UNITEN Student Centre is the project which had been completed, an interview providing a few questions was carried out to investigate the rate of UNITEN Student Centre utilization in the campus. The personnel interviewed in this research is the Student Representative Council members of UNITEN and the head of the Human Resource Department of Student Representative Council.

From the interview, the objectives of the centre were emphasized to ensure all the room and space was fully utilized according to the initial objectives. From the interview, it was found a few spaces were not fully utilized according to the personnel in charge.

\subsection{Value Engineering - Function Analysis}

This phase will determine the function of the project from the higher order to the lower order of the function. The function is divided into 3 types of function based on Dell 'Isola; basic function, secondary required function and secondary function [4]. In every project, there will always be the main function where the function is necessary and important for the project. To put it simply, no project would succeed if the main function is eliminated.

The higher order function of the renovation project is to create new students centre where this function shall not be removed. Then, how to create the student's centre was then shown in the green box where it is by providing meeting rooms, providing discussion rooms and activity hall as a mean for the students to carry out their activities. The functions highlighted in orange, representing the current design of the building where the functions are of the lower order functions. Fig. 4 shows the basic structure of the FAST diagram.

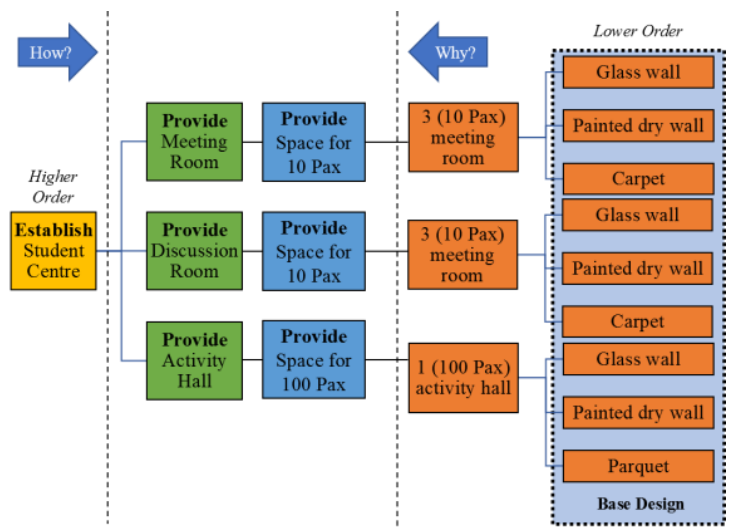

Fig. 4: The FAST Diagram

\subsection{Value Engineering - Creative Phase}

The alternatives were generated in the $3 \mathrm{D}$ model to be visualized easily as what might be changed after the alternatives. These tools will help personnel involved to directly consider the advantages and the disadvantages for each of the alternatives. From the FAST analysis, a few alternatives were listed to be evaluated as shown in Table 1. Fig. 5 shows the visualization of rooms in the 3D rendered model. The base design of the meeting room was designed with carpet flooring, glass wall and painted wall. The alternative design using drywall with wallpaper.

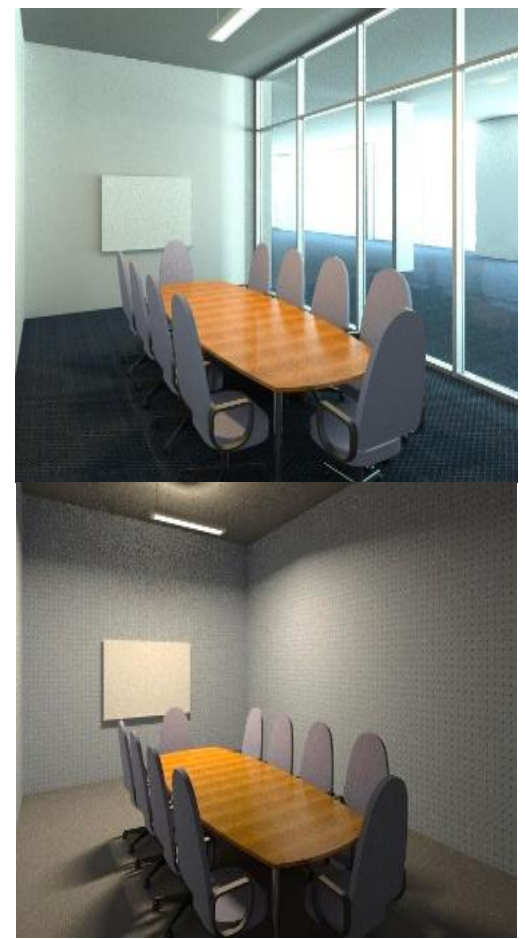

Fig. 5: Alternative 1 suggested (meeting room) 
Table 1: Base design and alternatives

\begin{tabular}{c|cc}
\hline $\begin{array}{c}\text { Base Interior } \\
\text { Design }\end{array}$ & \multicolumn{1}{c}{ Alternatives Interior Design } \\
\hline $\begin{array}{c}\text { Rooms: Carpet, } \\
\text { Glass Wall, }\end{array}$ & 1. $\begin{array}{l}\text { Cement render, partition drywall, } \\
\text { wallpaper for both rooms and hall }\end{array}$ \\
$\begin{array}{c}\text { Painted Wall } \\
\text { Hall: Parquet }\end{array}$ & 2. $\begin{array}{l}\text { Parquet flooring, partition drywall, } \\
\text { wallpaper for both rooms and hall } \\
\text { Flooring, Glass }\end{array}$ & $\begin{array}{l}\text { Change plan layout (enlarge the meeting } \\
\text { room) and use the based design for the hall }\end{array}$ \\
Wall, Painted Wall & \multicolumn{2}{|l}{}
\end{tabular}

\subsection{Value Engineering - Evaluation Phase}

Evaluation phase is where each of the alternatives was evaluated according to the equation of Value Engineering. In this study, the value was to be valued by multiplying the risk factor which consists of the cost index and the appearance of the design.

Value Index $=($ Performance $/$ Cost $) x$ Risk Index

Based on (1), the higher the performance index, then the higher the value index will be generated so is for the risk index. To evaluate the value index, the performance attributes were determined and decided, so the scale can be measured and compared. Table 2 shows the performance attributes determined for this project. The scale was divided into 5. Different projects will have different attributes depending on the objectives and necessity of the project.

Table 2: Base design and alternatives

\begin{tabular}{|c|c|c|c|}
\hline \multicolumn{2}{|c|}{ Performance Attributes } & Scale & Description \\
\hline \multirow{5}{*}{$\begin{array}{c}\text { Project } \\
\text { schedule / } \\
\text { Timings }\end{array}$} & \multirow{5}{*}{$\begin{array}{l}\text { The ability to } \\
\text { meet the con- } \\
\text { struction time } \\
\text { schedule: } \\
\text { USC Refur- } \\
\text { bishment pro- } \\
\text { ject } \\
\text { November } 2015 \\
\text { - July } 2016\end{array}$} & 5 & $\begin{array}{l}\text { Complete earlier by } \\
\text { more than } 1 \text { month }\end{array}$ \\
\hline & & 4 & $\begin{array}{c}\text { Complete earlier by } 1 \\
\text { month or less }\end{array}$ \\
\hline & & 3 & Completed on Time \\
\hline & & 2 & $\begin{array}{c}\text { Complete late by } 1 \\
\text { month or less }\end{array}$ \\
\hline & & 1 & $\begin{array}{c}\text { Complete late by more } \\
\text { than } 1 \text { month }\end{array}$ \\
\hline \multirow{5}{*}{ Quality Index } & \multirow{5}{*}{$\begin{array}{l}\text { Type of mate- } \\
\text { rial and its } \\
\text { maximum } \\
\text { material life- } \\
\text { span and dura- } \\
\text { bility }\end{array}$} & 5 & Last 10 years or more \\
\hline & & 4 & Last for $8-10$ years \\
\hline & & 3 & Last for $6-7$ years \\
\hline & & 2 & Last for $4-5$ years \\
\hline & & 1 & Last for 3 years or less \\
\hline
\end{tabular}

The risk attributes in Table. 3 were also generated according to the suitability of the project. As the study carried out was to optimize the cost, hence, one of the attributes decided was to control or to consider the cost risk for every alternative. Besides cost, the second attributes consider is the appearance of the room itself, where if the appearance is nice and cosy, then, it will be the added value for the alternative's design.

Table 3: Base design and alternatives

\begin{tabular}{|c|c|c|c|}
\hline \multicolumn{2}{|c|}{ Risk Analysis } & Scale & Description \\
\hline \multirow{5}{*}{ Cost Index } & \multirow{5}{*}{$\begin{array}{l}\text { Increment/ } \\
\text { reduction of } \\
\text { Cost from the } \\
\text { original cost }\end{array}$} & 5 & RM65/m $\mathrm{m}^{2}$ or less \\
\hline & & 4 & $\mathrm{RM} 66 / \mathrm{m}^{2}-\mathrm{RM} 70 / \mathrm{m}^{2}$ \\
\hline & & 3 & $\mathrm{RM} 71 / \mathrm{m}^{2}-\mathrm{RM} 75 / \mathrm{m}^{2}$ \\
\hline & & 2 & $\mathrm{RM} 76 / \mathrm{m}^{2}-\mathrm{RM} 80 / \mathrm{m}^{2}$ \\
\hline & & 1 & $\mathrm{RM} 81 / \mathrm{m}^{2}$ or more \\
\hline \multirow{5}{*}{ Appearance } & \multirow{5}{*}{$\begin{array}{l}\text { The Aesthetic } \\
\text { Value of the } \\
\text { design/room }\end{array}$} & 5 & Premium \\
\hline & & 4 & Attractive \\
\hline & & 3 & Moderate \\
\hline & & 2 & Dull \\
\hline & & 1 & Very Dull \\
\hline
\end{tabular}

Table 4: Base design and alternatives

\begin{tabular}{|c|c|c|c|c|c|}
\hline 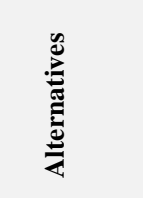 & 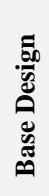 & 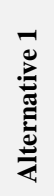 & & 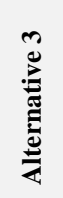 & 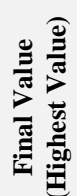 \\
\hline Objective 1 & 6.3 & 9.6 & 8.7 & 10.3 & 10.3 \\
\hline
\end{tabular}

\begin{tabular}{|c|c|c|c|c|c|}
\hline Objective 2 & 8.3 & 7.4 & 7.6 & 8.3 & 8.3 \\
\hline \multirow{2}{*}{ Total Project Value } & \multicolumn{4}{|c|}{ Before VE } & 14.6 \\
\cline { 2 - 5 } & \multicolumn{4}{|c|}{ After VE } & 18.6 \\
\hline \multicolumn{5}{|c|}{ Value Increment } & $+27.4 \%$ \\
\hline
\end{tabular}

The rightest column in Table 3 is the value where the highest value among the alternatives including the base concept is listed. The final value was then sum up and was compared to the base design value. Hence, from the evaluation, the value increment was $27.4 \%$ higher than the base value. Fig. 6 shows the 3D rendered image of the alternative 3 .

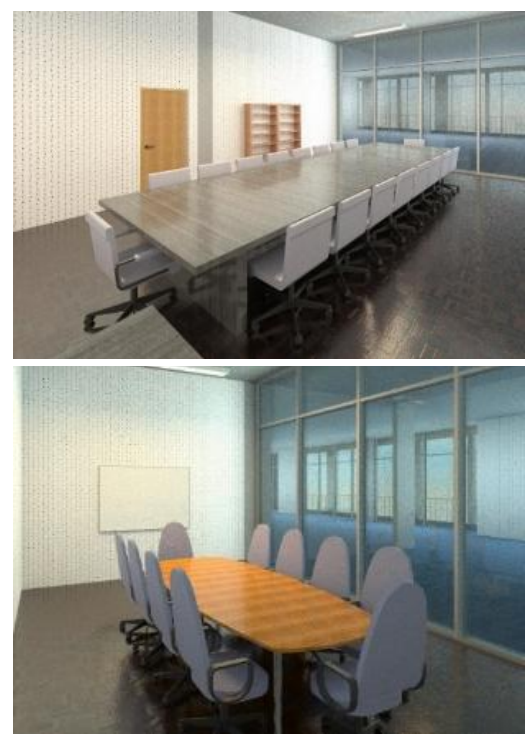

Fig. 6: The visualization of alternative 3

\subsection{Value Engineering - Life Cycle Cost Analysis}

Finally, the life-cycle cost of the alternatives was analysed. Considering the lifespan of the floor finishes for the project. As the product manufacturer was confidential, the lifespan was decided from the average lifespan for the common cases. Figure 7 shows the comparison of the life-cycle cost for each alternative. The most saving cost alternative is alternative number 1 where the lifecycle cost breakdown is approximately RM1, 273, 733.47 and the highest cost incur is the base design where approximately RM1, 458,263.80 for 30 years. Alternative 2 and 3 each incur approximately RM1, 296,895.12 and RM1, 286, 155.58.

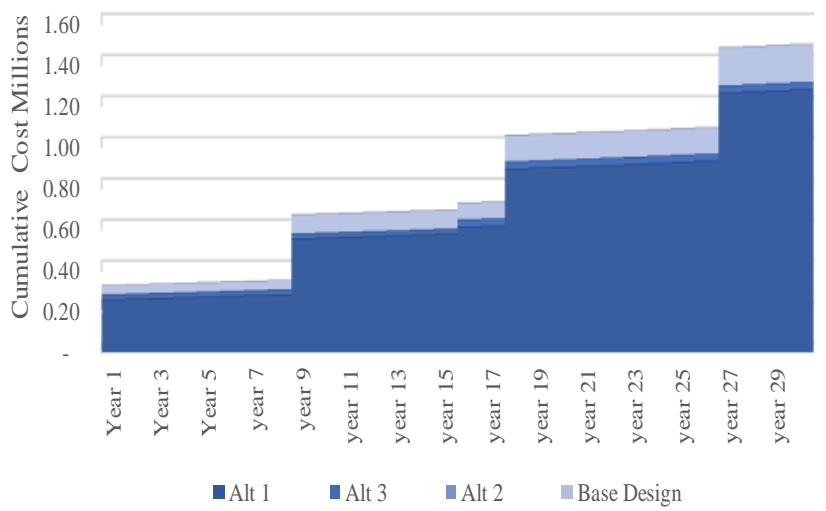

Fig. 7: Alternative 1 suggested (meeting room)

From Table 1 , the value index for alternative 3 calculated is the highest. Whereas, for LCCA, alternative 3 saved approximately RM 172,108.00 from the base design. Although, alternative 1 saved more compared to alternative 3 but since alternative 3 is higher in term of value index. Thus, Alternative 3 shall be chosen. The summarization of the analysis is shown in Table 2. 
Table 2: Summarization of Initial Cost and LCCA

\begin{tabular}{|c|c|c|}
\hline Alternatives & Initial Cost & $\begin{array}{c}\text { LCCA Cost } \\
\text { (30 years) }\end{array}$ \\
\hline Base Design & RM 285, 315.90 & RM 1, 458, 263.80 \\
\hline Alternative 1 & RM 251,964.71 & RM 1, 273,733.47 \\
\hline Alternative 2 & RM 261, 297.56 & RM 1, 296, 895.12 \\
\hline Alternative 3 & RM 259,353.78 & RM 1, 286, 155.58 \\
\hline
\end{tabular}

\section{Conclusion}

The VE exercise is indeed a very great system that shall be implemented in every industry as maximum as possible. The implementation would be much easier using BIM. Subsequently, cost reducing and value increasing can be achieved. Conventional construction system usually incurs a high cost of the project. In addition, the clashing and the fault often could only be detected during the construction phase which will add more to the cost incurred at the end of the project. Contrarily by implementing Value Engineering, the defect can be easily encountered during the design phase and they would be much easier with the help of BIM. Globally, there are still many factors hurdling this implementation although the driving factors have been positively agreed by many parties. The needs of all involved parties to learn the new system and tools might be a large influence factor for them to still be lacking in this system.

The study revealed that the hurdles of implementation of BIM in the industry is contributed the most by the awareness and the slow uptakes by the player involve in the current industry. This factor was found dominating $40 \%$ of the hurdles factor which is the highest among other factors Most of the personnel involved in the industry do not have the awareness to learn and adapt to the implementation as they will require a lot of time to learn and some even claim that this system will take over their job.

Meanwhile, the most influential factors in triggering the BIM implementation in the industry is the project performance which contributes $43 \%$ to the driving factors. Most of the research agreed that BIM implementation will certainly help to reduce the cost incur and the quality of the projects.

The study also revealed that by implementing VE in BIM for cost optimization, a large cost of the project can be saved. The initial cost generated for the floor finishes is RM 285,315.90 and the cost after the evaluation is RM 259, 353.78. The study shows that the cost can be optimized by approximately RM 30,000 from the base design. The evaluation also succeeds to increase the value by $27 \%$ where the base value is 14.6 and is increased to 18.6 respectively. This result is agreed with finding in [15] on cost saving.

The study conducted only consider the material provided by FDM where supposedly in the VE exercise every aspect including type and cost of the material should be considered. A cheaper material without compromising the quality of the products can also be considered to reduce cost but also increase the value concurrently. The study also considers only the floor finishes and the layout change in the floor plan with only 3 alternatives. It was certainly recommended that a wider range of options for the alternatives could also be suggested throughout the process to yield a higher value of the project

\section{Acknowledgement}

The authors would like to thank UNITEN R\&D Sdn. Bhd. for financial support through project grant No U-TS-CR-17-01 and for the opportunity to publish this paper.

\section{References}

[1] Park, C., Kim, H., Park, H., Goh, J., \& Pedro, A. (2017) ScienceDirect BIM-based idea bank for managing value engineering ideas. International Journal of Project Management, 35(4), 699-713. https://doi.org/10.1016/j.ijproman.2016.09.015

[2] Zhang, X., Mao, X., \& AbouRizk, S. M. (2009). Developing a knowledge management system for improved value engineering practices in the construction industry. Automation in Construction, 18(6), 777-789. https://doi.org/10.1016/j.autcon.2009.03.004

[3] Ranjbaran, Y., \& Moselhi, O. (2014). 4D-Base Value Engineering. Construction Research Congress 2014, ASCE 2014, 1606-1615.

[4] Alphonse Dell'isola, P. (1997). Value Engineering: Practical Application for Design, Construction, Maintenance \& Operations. RS Means.

[5] Memon, A. H., Rahman, I. A., \& Harman, N. M. E. (2014). Implementation of Building Information Modeling in Malaysian Construction Industry. $3^{\text {rd }}$ International Conference on Fundamental and Applied Sciences (ICFAS 2014): Innovative Research in Applied Sciences for a Sustainable Future, 349 (ICFAS), 343-349. https://doi.org/10.1063/1.4898490

[6] Vinita P Bhatija, Nithin Thomas, and Nashwan Dawood (2017), A Preliminary Approach towards Integrating Knowledge Management with Building Information Modeling (KBIM) for the Construction Industry, International Journal of Innovation, Management and Technology, Vol. 8, No. 1

[7] Smith, P. (2014). BIM implementation - Global strategies. Procedia Engineering, 85 , 482-492. https://doi.org/10.1016/j.proeng.2014.10.575

[8] Zahrizan, Z., Nasly, M. A., Ahmad, T. H., Marshall-Ponting, A., \& Zuhairi, A. H. (2013). Exploring the Barriers and Driving Factors in Implementing Building Information Modelling (BIM) in Malaysian Construction Industry: A Preliminary Study. IEM Journal, 75(1), 3 9.

[9] Grant, M. P., \& Nor, M. F. I. M. (2014). Building Information Modelling (BIM) in the Malaysian Architecture Industry, 10, 264 273.

[10] Construction Industry Development Board of Malaysia. (2015). BIM in Malaysia.

[11] Forgues, D., Iordanova, I., Valdivesio, F., \& Staub-French, S. (2012). Rethinking the Cost Estimating Process through 5D BIM: a case Study. Construction Research Congress 2012 (C) ASCE 2012, 778-786.

[12] Gerrish, T., Ruikar, K., Cook, M., Johnson, M., Phillip, M., \& Lowry, C. (2017). BIM application to building energy performance visualisation and managementChallenges and potential. Energy and Buildings, 144

$218-228$ https://doi.org/10.1016/j.enbuild.2017.03.032

[13] Yan, P., Xie, X., \& Meng, Y. (2014). Application of BIM Technique in Modern Project Management. Iccrem, 302-311. https://doi.org/10.1061/9780784413777.037

[14] Tulenheimo, R. (2015). Challenges of implementing new technologies in the world of BIM - Case study from construction engineering industry in Finland. Procedia Economics and Finance, 21(Henttinen 2012), 469-477. https://doi.org/10.1016/S2212 5671(15)00201-4

[15] Azhar, S. (2011). BIM: Trends, benefits, Risks and Challenges for the AEC Industry. Leadership Management in Engineering, 241252.

[16] Assaf, S. A. and Al-Hejii, S. (2006). Causes of Delay in Large Construction Projects. International Journal of Project Management 24(4), pp349-357.

[17] Sharma, A. (2012). Implementation of Value Engineering: A case Study, International Journal of Marketing, Finance Services and Management Researches, 1(3), pp. 64- 70.

[18] Al-Barami, A. (2010). Application of Value Engineering in Oman: MSc Thesis. School of Engineering and Design, Brunel University. 